\title{
Genetic Variability and Character Association Studies in Apple (Malus $\times$ domestica Borkh.)
}

\author{
Lokender Kumar $^{1 *}$, Rajesh Kumar Dogra ${ }^{2}$ and Ashu Chandel ${ }^{3}$ \\ ${ }^{1}$ Dept. of Fruit Science, ${ }^{3}$ Dept. of Basic Science, Dr YS Parmar University of Horticulture and \\ Forestry, Nauni, Solan, H.P. (173 230), India \\ *Corresponding author
}

Keywords

Apple, Variability,

Heritability,

Correlation coefficients, Path analysis, Yield

Article Info

Accepted:

20 July 2020

Available Online:

10 August 2020

\begin{abstract}
A B S T R A C T
Experiment was conducted to study the nature and magnitude of genetic variability in twelve genotypes of apple for various horticultural traits during 2018-19 in Kullu valley agroclimate of Himachal Pradesh, so as to identify promising traits on which selection can be made. Sufficient genetic variability was recorded among the genotypes under study. High heritability coupled with high genetic gain was found for the characters viz., trunk girth, tree spread, tree volume, titratable acidity, non-reducing sugars, sugar-acid ratio, fruit volume, fruit set and fruit drop. Yield per plant had shown positive and significant correlation with positive and significant association with trunk girth $(0.50)$ followed by tree spread (0.39) and annual shoot growth (0.34) at genotypic level. Path coefficient had positive direct effect towards fruit yield per tree: tree height (1.94), leaf area (1.33), trunk girth (1.08), fruit breadth (0.57), tree spread (0.29) and fruit weight (0.19). Suggesting that these parameters should be considered as prime traits during selection of desirable genotypes. The genotypes Scarlet Spur, Red Delicious were found promising for fruit length, fruit breadth, fruit weight, fruit volume, titratable acidity and non-reducing sugars whereas, Red Delicious V-22 was found promising for yield per plant (kg).
\end{abstract}

\section{Introduction}

Apple is economically the most important fruit tree crop due to its abundance in most of the temperate regions, fruit quality, longer shelf life and propagation ease. It is the most ubiquitous and well adapted species of temperate fruit crops. Apples have been cultivated since $4000 \mathrm{BC}$. The indigenous forms of apple have been known to exist for over two thousand years in the some of the temperate areas of India. First commercial cultivation of apple was done in Kullu valley of Himachal Pradesh (India) in 1870 (Hayes, 1957). It is a member of family Rosaceae and sub-family Pomoideae and genus Malus, order Rosales with a basic chromosome number of $x=17$. It has been originated in south western Asia, Asia Minor, the Caucasus mountains of Russia, central Asia and the Himalayan region of India and Pakistan (Juniper et al., 1999). Apple is the most cultivated and economically important fruit crop in temperate region of India. Its 
cultivation is mainly confined to the north western Himalayan region, comprising the states of Jammu and Kashmir, Himachal Pradesh and Uttarakhand. It can be grown at an altitude of 1500-2700 m above sea level. The chilling requirement ranges from 10001600 hours and well distributed rainfall of about $100-125 \mathrm{~cm}$ is sufficient for its cultivation. It is highly nutritious amongst fruits and is a good source of vitamin, carbohydrate and minerals. In Himachal Pradesh, apple has emerged as a leading cash crop amongst fruit crops. It has revolutionised the socio economic condition of the farmers of the state with 1, 11, 896 ha area under apple cultivation which accounts for the production of 4, 68, 134 MT fruits (Anonymous, 2017).

Genetic variability is the basis of all plant improvement programmes. Sufficient genetic variability if present can be exploited for developing superior cultivars. Vavilov (1951) was the first to realize that a wider range of variability in any crop provides a better chance of selecting the desirable types. Another important factor, besides genetic variation for characters is their transmission to the next generation. Knowledge of heritability for different traits is essential for any crop improvement programme because the heritable component is the consequence of genotype and is inherited from one generation to the other.

Apple cultivation is limited to the areas suitable for high chilling apple cultivars. Increase in average temperature, prolonged droughts during summers, negligible or no snowfall during winters has rendered large area of lower Kullu valley unfit for apple cultivation. The farmers' perceptions revealed changes in the snowfall pattern which led to depletion and shifting of ecological niche of traditionally and commercially important apple varieties, increase in low chill cultivars and shift of apple towards higher altitudes. It was also observed that the climate variability (reduction in snowfall, change in temperature and rainfall pattern) has caused the loss of vigour, fruit bearing ability, reduction in size of apple fruit and increasing attacks of pests resulting in low production and poor crop quality (Sen et al., 2015). Keeping in view, the present study was undertaken to estimate the genetic variability in respect of various quantitative and qualitative traits and to understand inherent relationship for fruit yield with various traits $v i s-a$ - vis to accomplish the cultivation of naturally acclimatized improved cultivars capable of withstanding biotic as well as abiotic stresses. In times to come they may also be employed in future crop improvement work.

\section{Materials and Methods}

The present investigation was carried out at Regional Horticultural Research and training Station, Bajaura, Seobagh, District Kullu during 2018-19, at an elevation of 1543 meters above mean sea level lying between latitude $31^{\circ} 99 \mathrm{~N}$ and longitude $77^{\circ} 13 \mathrm{E}$ witnessing mild temperate climate. The experimental material was comprised of twelve diverse genotypes viz. Red Chief, Vance Delicious, Oregon Spur II, Super Chief, Scarlet Gala, Gale Gala, Red Delicious, Top Red, Scarlet Spur Red Delicious, Early Red One, Red Fuji and Gold Spur. The plants were selected on the basis of the apparent yield performance and the past history of trees. During the course of study, all the recommended cultural practices were followed. Each single tree randomly selected in a genotype was considered as one replication.

Tree height and spread (East-west and NorthSouth) were measured with the help of measuring tape and were expressed in meters. The trunk girth was measured at a height of 
$10 \mathrm{~cm}$ above graft union with the help of measuring tape and was expressed in centimetres. Annual shoot growth was measured by randomly selecting five shoots on periphery of each tree and recording their extension growth before pruning and expressed in centimetres. The leaf area was measured in centimetre square with the help of leaf area meter (Licor-model 3100). The flowering character bearing habit was studied by observing the location of flowers whether they emerged on spurs or on shoots. Bud burst was recorded periodically. Number of days from the date of opening of first flower to the date of opening of last flower was taken as the duration of flowering. Fruits retained in all the cultivars were recorded one week before harvesting of fruits and expressed in percentage by dividing number of fruit retained with total number of flowers multiplied by 100 . Fruit drop was calculated in per cent by dividing number of fruit drop with number of fruit set multiplied by 100 .

The crop load of apples harvested from each plant was recorded and the results were expressed in yield per plant in kilograms. The length and diameters of fifteen fruits was measured with the help of digital Vernier calliper and mean was worked out and expressed in centimetres. The fruit weight was worked by weighing fifteen fruits selected randomly from each tree and weighed on a single pan kitchen balance and mean was expressed in grams. Fruit firmness was measured after removing the skin $(0.8 \mathrm{~cm})$ and using effigy penetrometer (model FT 327) with plunger of $11 \mathrm{~mm}$ diameter and expressed in $\mathrm{kg} / \mathrm{cm}^{2}$. The total soluble solids $\left({ }^{0} \mathrm{~B}\right)$ content in fruits were determined with the help of digital pocket refractometer (PalAt ago,Japan) after calibrating it with distilled water. Titrable acidity, total sugars, reducing sugars, non-reducing sugars were determined as per the method suggested by AOAC (1990).
The data recorded for each trait was analysed on mean values using standard Randomized Complete Block Design with three replications as described by Gomez and Gomez (1983).

Coefficient of variability at phenotypic, genotypic, environmental levels, Heritability (\%) in broad sense, expected genetic advance resulting from selection of five per cent superior individuals and genetic gain expressed as genetic advance per cent of population mean were calculated as per formula suggested by Burton and De Vane (1953) and Johanson et al., (1955), The genotypic and phenotypic correlation coefficients were calculated as per Al- Jibouri et al., (1958) by implying the techniques of statistical analysis in variance-covariance matrix analysis in which total variability had been split into replications, genotypes and errors. The phenotypic and genotypic correlation coefficients were used in finding out their direct and indirect contribution towards yield per tree. To have a deeper insight into, the direct and indirect effects of various yield components (independent variables) on dependent variables (fruit yield), the path coefficient analysis was worked out. Path coefficient analysis splits up the correlation coefficients between each pair of dependent variables and independent variables into a direct effect (path coefficient) and as indirect effects or via effects (path coefficient $\times$ correlation coefficient). Thus, the correlation coefficients between dependent variables and independent variables, which are of utmost importance, are the summation of direct and indirect effects. Path coefficient analysis was done by the method given by Dewey and Lu (1959).

\section{Results and Discussion}

The analysis of variance revealed the highly significant differences among the genotypes 
for all the twenty two traits studied indicating there is substantial genetic variability. The range, general mean, genotypic and phenotypic coefficient of variation, heritability and genetic advance in per cent of mean for all traits are presented in (Table 1). The results revealed that phenotypic coefficient of variation (PCV) was higher than its respective genotypic coefficient of variation $(\mathrm{GCV})$ for all the characters studied but minimal differences between them. The GCV helps in comparison and measurement of genetic variability among different characters. The estimation of phenotypic coefficient of variation was high for tree volume followed by yield efficiency. Low phenotypic coefficient of variation was recorded in reducing sugars followed by total sugars. The low variation indicated the highly stable nature of these characters among different genotypes studied and less scope of improvement in these characters.

The progress of breeding programme is conditioned by the magnitude and nature of genotypic and non-genotypic variation in the various characteristics. Since, most of the economic characters like yield are complex in inheritance and are greatly influenced by the various environmental conditions, the study of heritability and genetic gain is very useful in order to estimate the scope for improvement by selection. Heritability magnitude indicates the reliability with which the genotypes will be recognized by its phenotypic expression. High heritability coupled with high genetic gain was found for the characters viz., trunk girth, tree spread, tree volume, titratable acidity, non-reducing sugars, sugar-acid ratio, fruit volume, fruit set and fruit drop. Whereas, high heritability coupled with moderate genetic gain was obtained for characters viz., leaf area, total soluble solids, total sugars, reducing sugars, fruit weight and fruit firmness which indicated that the additive gene action had a strong influence on these characters and hence, for these traits simple selection procedure based on their phenotypic expression would be more reliable. Present studies are also supported by the findings of (Barua and Sharma (2002), Sharma et al., (2004), Singh et al., (2005), Hajnajari et al., (2012) and Srivastava et al., (2012) indicating the existence of significant variability, pointing plenty scope for their progress through selection.

The variation in correlation coefficient may be due to heterogeneous population having differences in genetic makeup of individual trees. The significant and positive correlation between different pairs can be helpful for genetic improvement of different characters in single step, if the higher or low value of each is required. While the negatively associated characters where increase or decrease in values of both the characters is required cannot be improved in a single step. The characters which had no significant correlation suggest that they are independent of each other. Fruit yield was taken as dependent variable. Genotypic and phenotypic correlation coefficients are presented in (Table 2). In general, the genotypic correlation coefficients were higher in magnitude than phenotypic correlation coefficients. The phenotypic correlation coefficients among studied characters showed that yield per tree had positive and significant association with trunk girth followed by tree spread and annual shoot growth indicating that selection of these traits would also lead to improvement in yield. Tree height was significantly correlated with annual shoot growth, tree volume, tree spread and trunk girth. Trunk girth was significantly correlated with tree spread, tree volume, yield per plant, annual shoot growth, titratable acidity and leaf area. Tree spread was significantly correlated with tree volume, leaf area, annual shoot growth, titratable acidity and yield. 
Table.1 Variability parameters of plant growth, flowering, fruiting and chemical characteristics of different apple genotypes

\begin{tabular}{|c|c|c|c|c|c|c|c|c|}
\hline \multirow[t]{2}{*}{ Sr. No } & \multirow[t]{2}{*}{ Trait } & \multirow[t]{2}{*}{ Mean } & \multirow[t]{2}{*}{ Range } & \multicolumn{2}{|c|}{ Coefficient of variation (\%) } & \multirow{2}{*}{$\begin{array}{c}\text { Heritability } \\
(\%)\end{array}$} & \multirow{2}{*}{$\begin{array}{l}\text { Genetic } \\
\text { advance }\end{array}$} & \multirow{2}{*}{$\begin{array}{c}\text { Genetic gain } \\
(\%)\end{array}$} \\
\hline & & & & Phenotypic & Genotypic & & & \\
\hline 1. & Tree height (m) & 30.48 & $2.96-5.59$ & 16.62 & 12.01 & 52.19 & 5.49 & 17.87 \\
\hline 2. & Trunk girth (cm) & 29.33 & $17.76-43.46$ & 26.25 & 21.42 & 66.61 & 10.56 & 36.02 \\
\hline 3. & Tree spread (m) & 2.48 & $1.62-3.68$ & 23.72 & 19.07 & 64.61 & 0.78 & 31.57 \\
\hline 4. & Tree volume $\left(\mathrm{m}^{3}\right)$ & 14.24 & $4.21-40.48$ & 76.09 & 63.93 & 70.60 & 15.75 & 110.66 \\
\hline 5. & Annual shoot growth (cm) & 31.09 & $23.55-38.71$ & 18.01 & 12.49 & 48.04 & 5.54 & 17.83 \\
\hline 6. & Leaf area $\left(\mathrm{cm}^{2}\right)$ & 33.52 & $28.80-38.57$ & 9.67 & 7.89 & 66.64 & 4.45 & 13.28 \\
\hline 7. & Duration of flowering (days) & 13.92 & $12.00-15.00$ & 9.64 & 5.52 & 32.74 & 0.91 & 6.50 \\
\hline 8. & Fruit length (mm) & 62.82 & $57.86-68.29$ & 5.50 & 4.39 & 63.78 & 4.54 & 7.23 \\
\hline 9. & Fruit breadth (mm) & 69.06 & $65.40-75.31$ & 5.60 & 3.07 & 36.70 & 2.64 & 3.83 \\
\hline 10. & Fruit weight (g) & 137.31 & $114.36-153.49$ & 8.70 & 7.81 & 80.60 & 19.83 & 14.44 \\
\hline 11. & Fruit volume (cc) & 14.53 & $10.16-18.33$ & 18.53 & 16.68 & 81.00 & 4.49 & 30.92 \\
\hline 12. & Fruit set $(\%)$ & 62.94 & $78.12-41.45$ & 15.09 & 14.19 & 88.36 & 17.29 & 27.47 \\
\hline 13. & Fruit drop (\%) & 30.43 & $20.32-42.23$ & 19.71 & 17.28 & 76.89 & 9.50 & 31.21 \\
\hline 14. & Yield/plant (kg) & 29.83 & $22.60-37.32$ & 20.70 & 13.02 & 39.89 & 5.05 & 16.94 \\
\hline 15. & Yield efficiency $\left(\mathrm{kg} / \mathrm{m}^{2}\right)$ & 5.06 & $2.04-9.44$ & 44.11 & 32.95 & 55.80 & 2.57 & 50.70 \\
\hline 16. & Fruit firmness $\left(\mathrm{kg} / \mathrm{cm}^{2}\right)$ & 13.29 & $11.87-15.26$ & 8.33 & 7.82 & 88.01 & 2.01 & 15.11 \\
\hline 17. & Total soluble solids $\left(\mathrm{B}^{\circ}\right)$ & 12.65 & $10.82-14.16$ & 8.28 & 8.10 & 95.55 & 2.06 & 16.30 \\
\hline 18. & Titratable acidity (\%) & 0.26 & $0.19-0.34$ & 19.34 & 17.55 & 82.37 & 0.08 & 32.81 \\
\hline 19. & Total sugars (\%) & 10.60 & $8.63-11.85$ & 8.59 & 8.51 & 98.20 & 1.84 & 17.37 \\
\hline 20. & Reducing sugars (\%) & 6.72 & $5.44-7.27$ & 7.41 & 7.23 & 95.06 & 0.98 & 14.52 \\
\hline 21. & Non-reducing sugars (\%) & 3.69 & $1.57-5.02$ & 24.22 & 23.84 & 96.86 & 1.78 & 48.33 \\
\hline 22. & Sugar acid ratio & 42.56 & $29.90-50.15$ & 19.35 & 17.11 & 78.20 & 13.27 & 31.18 \\
\hline
\end{tabular}


Table.2 Phenotypic and genotypic coefficient of correlation among different traits in different apple genotypes

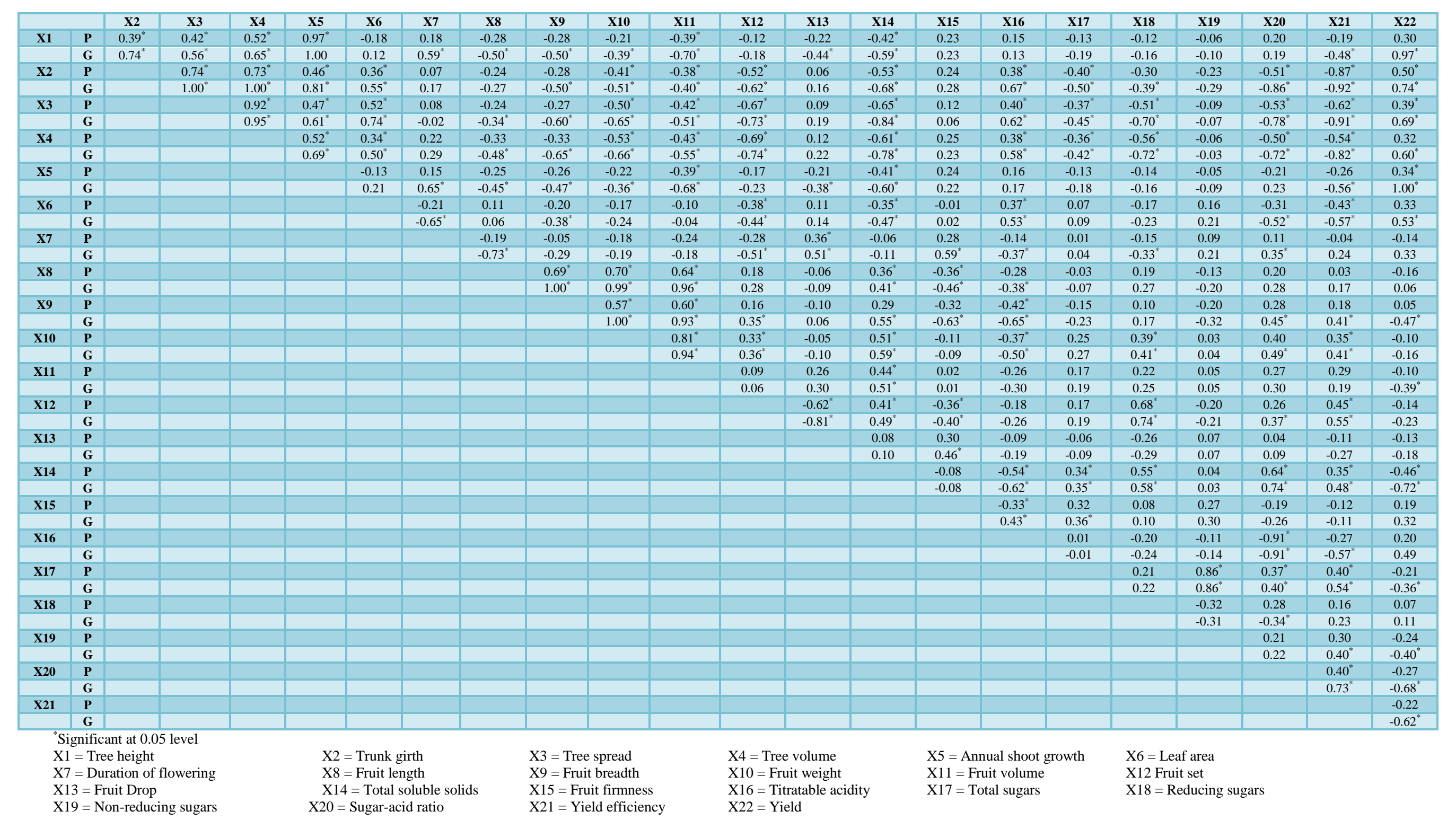


Table.3 Estimates of direct and indirect effects of different traits on yield of different apple genotypes

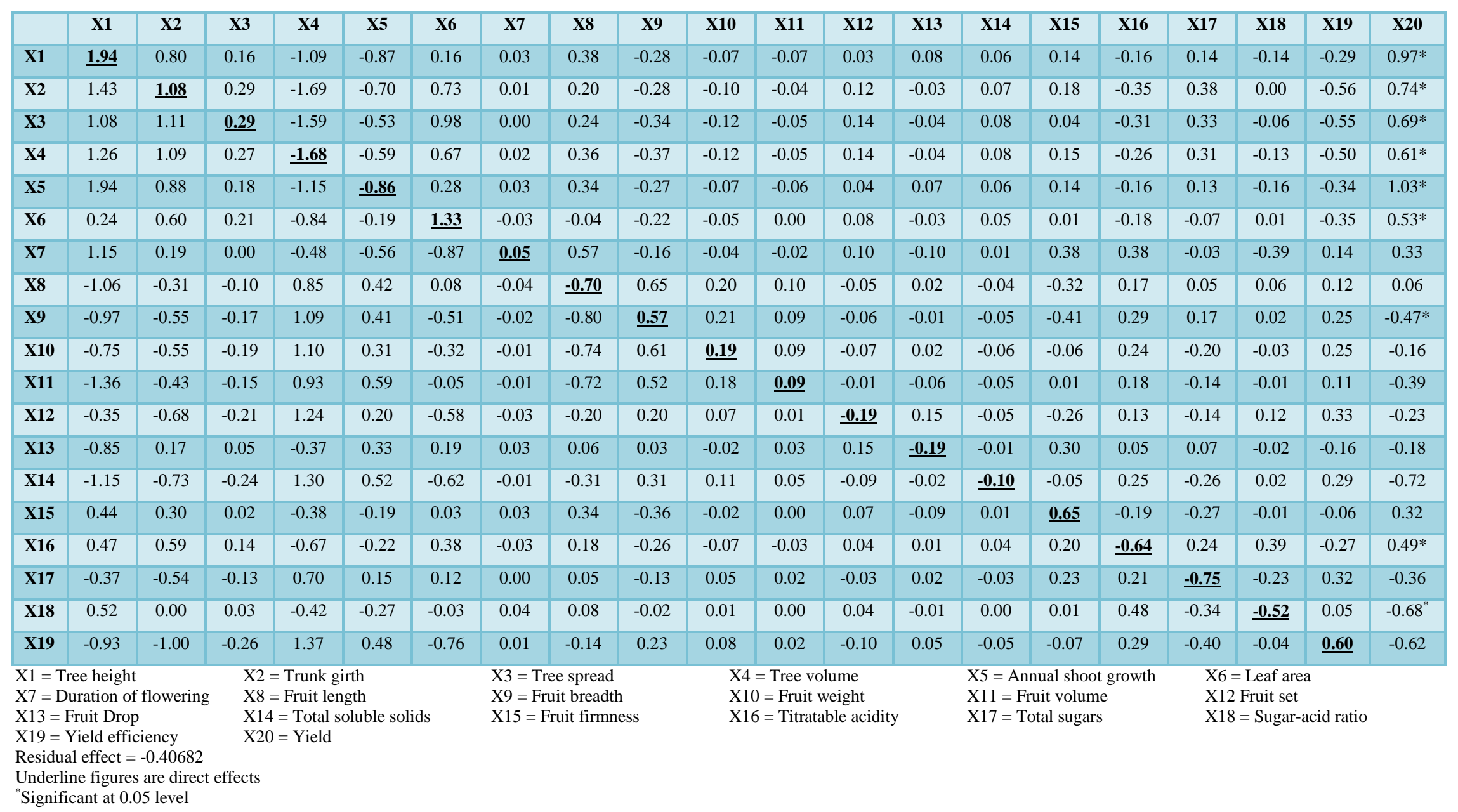


Tree volume was found to have significant correlation with annual shoot growth, titratable acidity and leaf area. Annual shoot growth was having significant positive correlation with yield. Leaf area showed positive and significant correlation with titratable acidity. Duration of flowering had positive and significant correlation with fruit drop. Fruit length was significantly correlated with fruit weight, fruit breadth, fruit volume and total soluble solids. Fruit breadth showed positive and significant correlation with fruit volume and fruit weight. However, Fruit weight showed positive and significant correlation with fruit volume, total soluble solids, reducing sugars, yield efficiency and fruit set. Fruit volume had positive and significant correlation with total soluble solids. Fruit set showed positive and significant correlation with reducing sugars, yield efficiency and total soluble solids. Fruit drop was positive but insignificant in phenotypic aspect with fruit firmness. Total soluble solids showed positive and significant correlation with sugar-acid ratio, reducing sugars, yield efficiency and total sugars. Fruit firmness showed negative and significant correlation with titratable acidity. Total sugars showed positive and significant correlation with non-reducing sugars, yield efficiency and sugar-acid ratio. Reducing sugars showed positive and insignificant in phenotypic aspect with sugar-acid ratio. Non-reducing sugars showed positive and insignificant in phenotypic aspect with yield efficiency. Sugar-acid ratio showed positive and significant phenotypic correlation with yield efficiency. The present findings are in close conformity with the earlier studies conducted by Barua and Sharma (2004), Hajnjari et al., (2012), Kumar and Mir (2012), and Srivastava et al., (2012).

Correlation study measures the mutual association without regard to causation, so, correlation may not always provide a true picture of association. The association becomes complex when many correlated characters are affecting the particular variable. In such situation, a path coefficient analysis enables to revaluate the direct effect of one cause on an effect and its indirect effect through other cause. In order to understand the causal factors of the correlation among traits studied, the estimates of direct and indirect effects were computed through path analysis and are presented in (Table 3). The path analysis revealed that positive direct effect on yield per plant was recorded for tree height, leaf area, trunk girth, fruit firmness, yield efficiency, fruit breadth, tree spread, and fruit weight. However, tree height showed positive indirect effect via trunk girth, fruit length, tree spread and leaf area and fruit firmness and total sugars. Trunk girth showed positive indirect effect via tree height, leaf area, total sugars, tree spread, fruit length, fruit firmness and fruit set. Tree spread showed positive indirect effect via trunk girth, tree height, leaf area, total sugars, fruit length and fruit set. Tree volume showed positive indirect effect via tree height, trunk girth, leaf area, fruit length, total sugars, tree spread, fruit firmness and fruit set. Annual shoot growth showed positive indirect effect via tree height, trunk girth, fruit length, leaf area, tree spread, fruit firmness and total sugars. Leaf area showed positive indirect effect via trunk girth, tree height, tree spread and fruit set. Duration of flowering showed positive indirect effect via tree height, fruit length, fruit firmness and titratable acidity, yield efficiency, trunk girth and fruit set. Fruit length showed positive indirect effect via tree volume, fruit breadth, annual shoot growth, fruit weight, titratable acidity, yield efficiency and fruit volume. Fruit breadth showed positive indirect effect via tree volume, annual shoot growth, titratable acidity, yield efficiency, fruit weight and total sugars. Fruit weight showed positive indirect effect via tree volume, fruit breadth, annual shoot growth, 
yield efficiency, titratable acidity and fruit volume. Fruit volume showed positive indirect effect via tree volume, annual shoot growth, fruit weight, titratable acidity and fruit weight and yield efficiency. Fruit set showed positive indirect effect tree volume, yield efficiency, annual shoot growth and fruit breadth, fruit drop, titratable acidity and sugar acid ratio. Fruit drop showed positive indirect effect via annual shoot growth, fruit firmness, leaf area, trunk girth and fruit set. Total soluble solids showed positive indirect effect via tree volume, annual shoot growth, fruit breadth, yield efficiency, titratable acidity and fruit weight. Fruit firmness showed positive indirect effect via tree height, fruit length, trunk girth and fruit set. Titratable acidity showed positive indirect effect via trunk girth, tree height, sugar-acid ratio leaf area, total sugars, fruit firmness, fruit length and tree spread. Total sugars showed positive indirect effect via tree volume, yield efficiency, fruit firmness, titratable acidity, annual shoot growth and leaf area. Sugar-acid ratio showed positive indirect effect tree height, titratable acidity and fruit length. Yield efficiency showed positive indirect effect via tree volume, annual shoot growth, titratable acidity, fruit breadth and fruit weight. These results are in close conformity with the findings of Barua and Sharma (2004) and Bharti et al., (2016).

In conclusions to find out the suitable genotypes for recommendation for cultivation in the prevailing environment conditions in Kullu valley of Himachal Pradesh the available germplasm was screened. Genetic variation for all the traits under study was observed. The interrelationship among various traits revealed that the tree characteristics trunk girth, tree spread, tree volume, annual shoot growth and fruiting characteristics fruit volume, fruit set and fruit weight were important for selecting a desirable genotype in apple. On the basis of overall performance, the genotypes Scarlet Spur Red Delicious followed by Red Chief, Super Chief found promising for fruit length, fruit breadth, fruit weight, fruit volume, titratable acidity and non-reducing sugars whereas Red Delicious V-22 was found promising for yield per plant $(\mathrm{kg})$.

\section{References}

Al-Jibouri, H.A., Miller, P.A. and Robinson, H.F. 1958. Genotypic and environmental variances and covariances in an upland cotton cross of interspecific origin. Agronomy J., 50:633-636.

Anonymous. 2017. Horticultural development in Himachal Pradesh at a glance. www.hpagrisnet.gov.in.

AOAC. 1990. Official Methods of Analysis. $15^{\text {th }}$ edition. Hortwitz, W. Washington, DC. 1015 p.

Barua, U. and Sharma, R.K. 2002. Genetic variability studies in apple (Malus $\times$ domestica Borkh.) Progressive Hort. 34:187-191.

Barua, U. and Sharma, R.K. 2004. Correlation and path analysis studies in apple. Indian J. of Hort., 61:18-23.

Bharti. Mahajan, P.K. and Chandel, A. 2016. Correlation and path analysis for yield and its morphological characters in apple tree (Malus $\times$ domestica Borkh.). Green Farming., 7:1070-1072.

Burton, G.W., and De Vane, E.H. 1953. Estimating heritability in tall fescue (Festuca arundinacea) from replicated clonal material. Agronomy J., 45:478481.

Dewey, J.R. and Lu, K.H. 1959. Correlation and path analysis of components of crested wheat grass seed production. Agronomy J., 51:515-518.

Gomez, K.A. and Gomez, A.A. 1983. Statistical Procedures for Agricultural Research. John Wiley and Sons Inc., 
New York. 357-427.

Hajnajari, H., Chashnidel, B., Vahdati, K., Ebrahimi, M., Nabipour, A. and Fallahi, E. 2012. Heritability of morphological traits in apple earlyripening full-sib and half offspring and its potential use for assisted selection. Hort. Sci., 47:328-333.

Hayes, W.B. 1957. Fruit growing in India. Kitabstan, Allahabad, India. 439p.

Johanson, H.W., Robinson, H.F., and Comstock, R.E. 1955. Estimates of genetic and environment variability in soyabean. Agronomy J. 47:314-318.

Juniper, B.E., Watkin, R., and Harries, S.A. 1999. The origin of apple. Acta Horti., 484:27-30.

Kumar, A., and Mir, M.Y. 2012. Varietal assessment, heritability estimates and correlation studies in apple cultivars of South Kashmir. J. of Horti. Sci., 7:8184.

Sen, V., Rana R.S., Chauhan, R.C., and Aditya. 2015. Impact of climate variability on apple production and diversity in Kullu Valley, Himachal Pradesh. Indian J. of Horti., 72:14-20.

Sharma, G., Chua, G.D., and Sharma, O.C. 2004. Studies on evaluation and variability parameters in low chilling apples (Malus $\times$ domestica Borkh.). Acta Horti., 662:19-22.

Singh, S.C., Pant, K.P., Dimri, D.C., and Nautiyal, M. C. 2005. A note on flowering season and fruit characteristics of some apple cultivars. Acta Horti., 696:49-51.

Srivastava, K.K., Das, B., Ahmed, N., Singh, S.S., Rather, J. A., and Bhat, S.K. 2012. Correlation and co-heritability studies of yield and yield-associating characters in apple (Malus $\times$ domestica Borkh.). Indian J. of Agri. Sci., 82:270276.

Vavilov, N.I. 1951. The origion, variation, immunity and breeding of cultivated plants. Chronica Botanica., 13:1-366.

\section{How to cite this article:}

Lokender Kumar, Rajesh Kumar Dogra and Ashu Chandel. 2020. Genetic Variability and Character Association Studies in Apple (Malus $\times$ domestica Borkh.). Int.J.Curr.Microbiol.App.Sci. 9(08): 2230-2239. doi: https://doi.org/10.20546/ijcmas.2020.908.256 